\title{
Modulation of Dopamine Efflux in the Nucleus Accumbens after Cholinergic Stimulation of the Ventral Tegmental Area in Intact, Pedunculopontine Tegmental Nucleus-Lesioned, and Laterodorsal Tegmental Nucleus-Lesioned Rats
}

\author{
Charles D. Blaha, ${ }^{1}$ Laura F. Allen, ${ }^{3}$ Sheela Das, ${ }^{2}$ Wendy L. Inglis, ${ }^{4}$ Mary P. Latimer, ${ }^{3}$ Steven R. Vincent, ${ }^{2}$ and \\ Philip Winn ${ }^{3}$ \\ Departments of ${ }^{1}$ Psychology and ${ }^{2}$ Psychiatry, University of British Columbia, Vancouver, British Columbia, \\ Canada V6T 1Z4, ${ }^{3 S}$ Chool of Psychology, University of St. Andrews, St. Andrews, Fife KY16 9JU, United Kingdom, and \\ ${ }^{4}$ Department of Anatomy and Neurobiology, Dalhousie University, Halifax, Nova Scotia, Canada B3H 4HI
}

\begin{abstract}
Microinjections of the cholinergic receptor agonist nicotine and the cholinesterase inhibitor neostigmine were made into the ventral tegmental area (VTA) of urethane-anesthetized rats, and dopamine (DA) efflux in the nucleus accumbens was measured using in vivo chronoamperometry. Dose-dependent increases in the chronoamperometric signals corresponding to increased DA efflux were observed in the nucleus accumbens of normal intact rats after cholinergic stimulation of the VTA. The source of the cholinergic input to the VTA was investigated by making excitotoxic lesions in either the laterodorsal tegmental nucleus (LDTg) or the pedunculopontine tegmental nucleus (PPTg). Compared with sham-operated control animals, which showed the same response as intact, nonlesioned rats, ibotenate lesions of the LDTg attenuated the stimulatory effects of intraVTA neostigmine on DA efflux in the nucleus accumbens. In
\end{abstract}

contrast, rats with ibotenate lesions of the PPTg showed normal nucleus accumbens DA efflux after intra-VTA injections of neostigmine. Such lesions in the PPTg attenuate DA efflux in the caudate-putamen stimulated by injections of neostigmine into the substantia nigra pars compacta (SNc). The present data show that cholinergic neurons in the LDTg, but not the PPTg, regulate the activity of DA-containing neurons in the VTA, which complements previous data showing that cholinergic neurons in the PPTg regulate DA-containing neurons in the SNc.

Key words: ventral tegmental area; nucleus accumbens; laterodorsal tegmental nucleus; pedunculopontine tegmental nucleus; dopamine; acetylcholine; ibotenate; chronoamperometry; rat
Dopamine (DA)-containing neurons in the substantia nigra pars compacta $(\mathrm{SNc})$ receive cholinergic innervation from the pedunculopontine tegmental nucleus (PPTg). This has been shown by tracing studies (Woolf and Butcher, 1986; Beninato and Spencer, 1987, 1988; Clarke et al., 1987; Tokuno et al., 1988; Gould et al., 1989; Lavoie and Parent, 1994) (but see also Lee et al., 1988), electron microscopic studies (Bolam et al., 1991), and functional examinations (Hernandez-Lopez et al., 1992; Blaha and Winn, 1993). This is consistent with the observation that acetylcholine (ACh), together with its synthetic enzyme choline acetyltransferase (CAT), and degradative enzyme acetylcholinesterase $(\mathrm{AChE})$ are present in the substantia nigra (Jacobowitz and Goldberg, 1977; Butcher and Marchand, 1978; Lehmann and Fibiger, 1978; Greenfield et al., 1980), as are both muscarinic and nicotinic receptors, at which $\mathrm{ACh}$ has excitatory actions (Clarke et al., 1985; Lacey et al., 1990; Nastuk and Graybiel, 1991). Behavioral studies also support the hypothesis that cholinergic systems interact with DA neurons in the SNc (Parker et al., 1991, 1993; Winn, 1991).

Received June 7, 1995; revised Oct. 10, 1995; accepted Oct. 12, 1995.

This work was supported by a Nato Collaborative Research grant to C.D.B. and P.W., and by the Wellcomc Trust. C.D.B. is a Canadian MRC Scholar. L.F.A. and W.L.I. were Wellcome Trust Prize students. We thank Dr. A. G. Phillips, FRSC Catriona Wilson, Dennis Fiorino, Dr. V. J. Brown, and Dr. H. C. Fibiger for their advice and technical assistance.

Correspondence should be addressed to Dr. Winn at the above address.

Copyright (C) 1996 Society for Neuroscience $0270-6474 / 96 / 160714-09 \$ 05.00 / 0$
DA neurons in the ventral tegmental area (VTA) also are cholinoceptive. Nicotinic receptors are present in the VTA (Clarke and Pert, 1985), and the behavioral effects of cholinergic drugs are consistent with stimulation of these receptors (Druhan et al., 1989). Moreover, systemically administered nicotine increases DA efflux in the nucleus accumbens by acting in part in the VTA (Nisell et al., 1994). However, the source of the cholinergic input to VTA DA neurons has not been investigated in detail. It is unclear to what extent the cholinergic neurons of either the PPTg or the laterodorsal tegmental nucleus (LDTg) innervate the VTA. Ascending fibers from the PPTg appear to run through the VTA, possibly making synaptic contact (Hallanger and Wainer, 1988), but a more prominent innervation from the LDTg has been described previously (Satoh and. Fibiger, 1986; Cornwall et al., 1990). In a previous study, we assessed the relationships among the PPTg, SNc, and caudate-putamen (Blaha and Winn, 1993). Injections into the $\mathrm{SNc}$ of cholinergic receptor agonists or the anticholinesterase neostigmine increased DA eflux in the ipsilateral caudate-putamen, measured by both in vivo electrochemistry and microdialysis. In rats with excitotoxic lesions of the PPTg, however, the amount of caudate-putamen DA efflux stimulated by neostigmine was attenuated, whereas the response to nicotine was enhanced. Because the PPTg lesions spared LDTg cholinergic neurons completely, yet postsynaptic receptor supersensitivity in the SNc developed, it was argued that the cholinergic innervation of the SNc must come almost exclusively from the PPTg. 
In these cxperiments, we have adopted the same rationale to investigate the cholinergic innervation of the VTA. In our previous experiments (Blaha and Winn, 1993), we used both in vivo microdialysis and electrochemical techniques to cross-validate results. Having done this, we have chosen to use only in vivo electrochemistry in the present study, which was designed to determine the following: (1) whether cholinergic receptor agonists and cholinesterase inhibitors increase DA activity in the nuclcus accumbens after microinjection into the VTA; and (2) whether PPTg or LDTg lesions remove cholinergic input to the VTA and consequently diminish the response to AChE inhibitors.

\section{MATERIALS AND METHODS}

Subjects. Male hooded Long-Evans rats weighing $350-450 \mathrm{gm}$ werc used in all experiments. Animals were housed in individual stainless steel cages at constant room temperature $\left(24^{\circ} \mathrm{C}, 60 \%\right.$ relative humidity) and maintained on a $12 \mathrm{hr}$ light/12 hr dark cycle (lights on at 7:00 A.M.). Food and water were available ad libitum.

Electrochemical studies. Rats were ancsthetized with urethane $(2 \mathrm{gm} /$ $\mathrm{kg}$, i.p.) and placed in a stereotaxic (rame. Body temperature was maintained at $37^{\circ} \mathrm{C}$ with a temperature-controlled water-heating pad (American Hospital Supplies, McGraw Park, IL). Stearate-modified graphite paste recording electrodes [prepared as described previously (Blaha and Lane, 1983)], which allow in vivo measurement of changes in DA cfflux without interference from other oxidizable compounds in brain extracellular fluid (Blaha and Jung, 1991), were implanted stereotaxically into each nucleus accumbens (coordinates: $+1.5 \mathrm{~mm}$ from the bregma, \pm 1.3 $\mathrm{mm}$ from the midline, $-6.5 \mathrm{~mm}$ from the dura mater, with skull level) (Paxinos and Watson, 1986). An Ag/AgCl reference and a stainless steel auxiliary electrode combination were placed in contact with cortical tissue $4 \mathrm{~mm}$ posterior to the bregma. Repctitive chronoamperometric measurements were made using an electrometer (Echempro, Vancouver, BC, Canada), and DA efflux was monitored by applying a potential pulse from -0.15 to $+0.25 \mathrm{~V}$ versus $\mathrm{Ag} / \mathrm{AgCl}$ to the recording electrode for $1 \mathrm{sec}$ at $30 \mathrm{sec}$ intervals and monitoring the DA oxidation current at the end of each 1 sec pulse. Changes in DA efflux in the nucleus accumbens observed after drug administration were expressed as percent change from baseline and were derived as in Blaha and Winn (1993). Drug-induced changes in DA oxidation current were calculated as absolute current values taken from the preinjection baseline of each drug to the observed peak effect and were expressed as percent change with respect to the mean baseline current valuc given above (Blaha et al., 1990; Blaha and Phillips, 1992).

Drug microinjections. Drug solutions were back-loaded into a 30 gauge stainless steel cannula $\left(90^{\circ}\right.$ bevel) connected via PE10 tubing to a $5.0 \mu \mathrm{l}$ microsyringe (Scicntific Glass Engineering, Ringwood, Australia) mounted in an infusion pump (Harvard Pump 22). After stable baseline recordings from both clectrodes of $60-120 \mathrm{~min}$, the infusion cannula was inserted in graduated steps over a 15 min period into the VTA (coordinates: $+3.4 \mathrm{~mm}$ from the interaural line, $+1.0 \mathrm{~mm}$ lateral to midline, $-8.0 \mathrm{~mm}$ from the dura mater, with skull surfacc level) (Paxinos and Watson, 1986). After an additional $10 \mathrm{~min}$ baseline recording, ncostigmine (0.5 or $1.0 \mathrm{~mm}$; Sigma, St. Louis, MO), nicotine $(0.2$ or $2.0 \mathrm{~mm}$; Sigma), or saline $(0.9 \% \mathrm{NaCl})$ was microinjected into the VTA in a volume of $0.25 \mu$ over 2 min. Microinjection progress was monitored by observing the movement of a small air bubble deliberately placed in the PE10 line; 10 min after infusion, the cannula was retracted slowly out of the brain.

Excitotoxic lesions of the LDTg and PPTg. Rats were anesthetized with $30 \mathrm{mg} / \mathrm{kg}$ sodium pentobarbitone (Somnotol, $65 \mathrm{mg} / \mathrm{ml}$ sodium pentobarbital; MTC Pharmaceuticals, Cambridge, Ontario, Canada) and placed in a stereotaxic frame. Unilateral lesions of the LDTg were made by injection of $20 \mathrm{nmol}$ of ibotenic acid (Cambridge Rescarch Biochemicals, Cheshire, UK; $0.4 \mu \mathrm{l}, 0.05 \mathrm{~m}$ ) with a $1 \mu \mathrm{l}$ syringe (Scientific Glass Engineering) mounted on the stereotaxic frame. Ibotenate was dissolved in phosphate buffer, pII 7.4, and the final pII of the solution was adjusted with $2 \mathrm{M} \mathrm{NaOH}$ to 7.2. The infusions were made using a step-down procedure of $0.02 \mu \mathrm{l} / 10 \mathrm{sec}$ with an additional $300 \mathrm{sec}$ in situ to allow for toxin diffusion before retraction of the needle. Care was taken to ensure that the beveled face of the needle always pointed rostrally. The injection needle was angled $20^{\circ}$ vertical to ensure that the cannula did not penetrate the cerebral aqueduct or fourth ventricle. The following stereotaxic coordinates were uscd: anteroposterior, $+0.2 \mathrm{~mm}$ from interaural line; lateral, $+3.3 \mathrm{~mm}$ from midline; ventral, $-7.2 \mathrm{~mm}$ from skull surface; with skull level (Paxinos and Watson, 1986). To make lesions in the PPTg, two injections were made at the following stereotaxic coordinates: (1) anteroposterior, $+0.8 \mathrm{~mm}$ from interaural line; lateral, $+1.6 \mathrm{~mm}$ from midline; ventral, $-7.0 \mathrm{~mm}$ from skull surface; and (2) anteroposterior, $+1.5 \mathrm{~mm}$ from interaural line and $\pm 1.7 \mathrm{~mm}$ from midline; ventral, $-7.8 \mathrm{~mm}$ from skull surface; with skull level (Paxinos and Watson, 1986). The infusions were made using the step-down procedure described above. At each site in the PPTg, rats received an injection of $24 \mathrm{nmol}(0.2 \mu \mathrm{l} \times 0.12 \mathrm{M})$ of ibotenic acid. Control rats were injected with phosphate buffer vehicle only (using either LDTg or PPTg lesion parameters). All rats were observed in the immediate postoperative period; excitotoxic lesions were followed by postural deviation, barrel rolling, forepaw treading, and rotation, hich generally lasted $<2 \mathrm{hr}$. When this activity stopped, rats were returned to the home-cage room. Determination of DA efflux in the nucleus accumbens in response to VTA cholinergic stimulation (neostigminc, $0.5 \mathrm{mM}$ ) was cxamined using standard procedures $15-19$ days after the lesions had been made.

Histological analysis. For the nonlesioned rats, after completion of each acute electrochemical experiment the brain was removed and placed in $10 \%$ buffered formalin. After fixation, $50 \mu \mathrm{m}$ sections were cut on a cryostat and stained for Nissl substance with cresyl violet. The PPTg-, LDTg-, and sham-lesioned rats were perfused under deep anesthesia with phosphate-buffered saline followed by $4 \%$-formaldehyde in $0.1 \mathrm{~m}$ phosphate buffer. Two parallel sets of $50 \mu \mathrm{m}$ sections were cut $200 \mu \mathrm{m}$ apart through the PPTg and LDTg (from the posterior substantia nigra to the posterior locus ccrulcus). One set of sections was stained using cresyl violet for the determination of lesion volumes, and a sccond set of sections was stained for nicotinamide adenine dinucleotide phosphate (NADPH) diaphorase using a modification of the procedure of Vincent and Kimura (1992). The locations of cannulae tracks in all rats were determined from Nissl-stained sections. Silhoucttes of lesions were drawn onto representative sections of the rat brain (Swanson, 1992), and the number of NADPH diaphorase-positive neurons in the PPTg, LDTg, and subpeduncular tegmental nucleus was counted. All histological assessment was conducted by M.P.L., blind with respect to lesion condition.

Statistical analysis. Statistical analysis of data was undertaken using analysis of variance with Tukey's post hoc tests.

\section{RESULTS}

\section{Cannulae and electrode placements}

Figure 1 shows representative placements of cannulae in the VTA, where there was close clustering of injection sites, and electrochemical electrodes in the nucleus accumbens.

\section{Effects of intra-VTA nicotine and neostigmine on DA efflux in the nucleus accumbens}

As shown in Figure 2, $A$ and $B$, microinjection of 0.2 and $2.0 \mathrm{~mm}$ nicotine into the VTA increased the chronoamperometric signals corresponding to $\mathrm{D} \Lambda$ efflux in the nucleus accumbens, in contrast to microinjcctions of saline, which were without effect. DA efflux in the nucleus accumbens reached maximal increases of $132 \pm 4$ and $276 \pm 14 \%$ (Table 1 ) with respect to baseline levels $(0.95 \mathrm{nA}$, $100 \%$ ) within 50 and 85 min after injection, respectively. The total duration of action for these effects was 90 and $180 \mathrm{~min}$ for 0.2 and $2.0 \mathrm{~mm}$, respectively. Microinjection of the anticholinesterase neostigmine into the VTA resulted in potent enhancement of the chronoamperometric signals recorded in the nucleus accumbens (Fig. 2C,L); Table 1). Maximal increases in accumbens DA efflux of $580 \pm 36$ and $1044 \pm 49 \%$ were observed within 95 and $50 \mathrm{~min}$ after microinjection of nicotine into the VTA at doses of 0.5 and $1.0 \mathrm{~mm}$, respectively. The total duration for the stimulatory effects of $0.5 \mathrm{~mm}$ neostigmine on nucleus accumbens DA efflux was 210 min. At the higher dose of $1.0 \mathrm{~mm}$ neostigmine, the response remained elevated at approximately half-maximal over the course of the experiment.

\section{Effects of mesopontine ibotenate lesions}

Figure 3 shows schematic representations of the largest and smallest PPTg and LDTg lesions, and Figure 4 shows representative 


\section{VTA cannula placements}

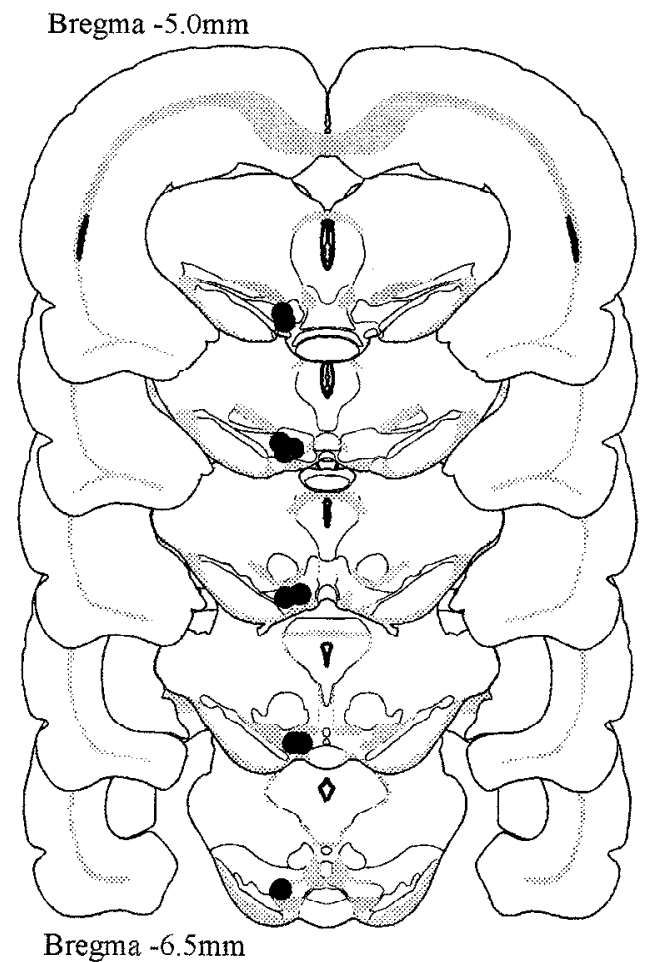

\section{N. Accumbens electrode placements}

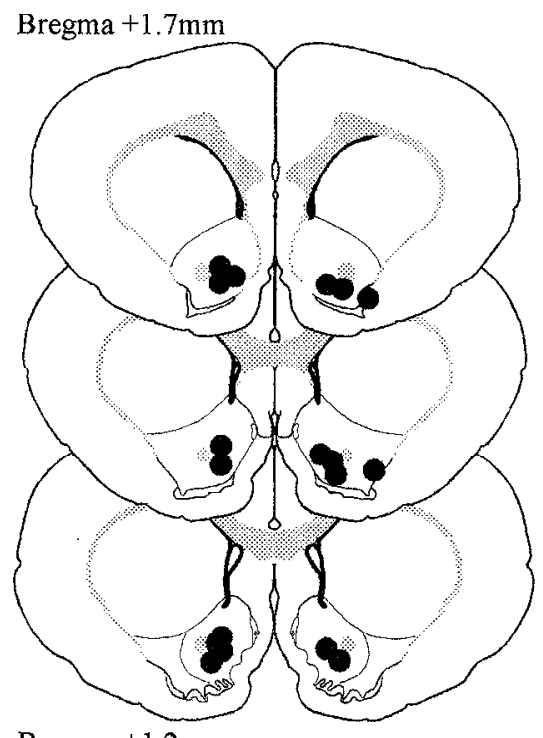

Bregma $+1.2 \mathrm{~mm}$

Ipsilateral Contralateral Sections show the placement of electrochemical electrodes in the nucleus accumbens (sections from Swanson, 1992).

Figure 1. Left, Sections show the placement of microinjection cannulae the VTA. Placements were tightly clustered; those shown indicate the an teroposterior, mediolateral, and dor- photomicrographs of LDTg and PPTg lesions. Together, these figures show that there was no overlap between the two lesions. PPTg lesions extended from a point just caudal to the substantia nigra and extended caudally almost to the parabrachial nuclei. There was no invasion of the central gray and no damage in the substantia nigra, although neurons were lost from other structures adjacent to the PPTg. Damage in these structures (deep mesencephalic nucleus, cuneiform nucleus, and retrorubral nucleus) was never complete and varied among rats, making it unlikely that this partial and inconsistent damage affected the results of these experiments. LDTg lesions, in contrast, tended to be contained within the central gray matter, with leakage into the tissue immediately above and below the superior cerebellar peduncle in the cuneiform and medial parabrachial nuclei in some cases. As with the PPTg, damage to these structures was only partial and was not consistent across all rats. Table 2 presents counts of diaphorasepositive neurons in the PPTg, LDTg, and subpeduncular tegmental nucleus (SPTg) in the three groups of rats, and average lesion volumes were computed from analysis of Nissl-stained sections. The diaphorase counts show clearly that ibotenate directed at the PPTg destroyed neurons there but not in the LDTg, whereas ibotenate injected into the LDTg destroyed neurons there but not in the PPTy. Loss of diaphorase-positive neurons was seen in the SPTg after some LDTg lesions but never after PPTg lesions. The lesions made in the PPTg were similar in size to those reported previously (Dunbar et al., 1992; Rugg et al., 1992; Inglis et al., $1994 \mathrm{a}, \mathrm{b})$; to the best of our knowledge, excitotoxic lesions of the LDTg have not been reported previously.

As shown in Figure 5, microinjection of $0.5 \mathrm{~mm}$ neostigmine into the VTA of LDTg-lesioned rats resulted in an attenuated increase in the chronoamperometric signals in the nucleus accum- bens compared with the neostigmine-induced increases in accumbens DA efflux observed in sham-lesioned control rats. Peak neostigmine-induced increases in accumbens DA efflux occurred $90 \mathrm{~min}$ after infusion; neither sham-lesioned $(591 \pm 39 \%)$ nor PPTg-lesioned $(523 \pm 22 \%)$ rats differed significantly in their response to VTA neostigmine compared with intact controls (580 $\pm 36 \%)$. DA efflux in the accumbens of LD'lg-lesioned rats reached maximal increases of $235 \pm 11 \%$ within 95 min after injection of neostigmine (Fig. 2C; Table 1). The total duration of action for these effects was similar to those observed in intact and sham-lesioned animals (210 min; Fig. $5 A, B$ ).

\section{DISCUSSION}

\section{ACh in the VTA and nucleus accumbens DA}

The data presented in this paper show that cholinergic stimulation of the VTA increased the DA concentration in the extracellular space of the nucleus accumbens. Both nicotinic receptor stimulation and cholinesterase inhibition with neostigmine produced clear dose-dependent effects. These data are consistent with the observation that VTA neurons have cholinergic receptors on their somatodendritic membranes and that activation of these neurons generally is excitatory (Clarke and Pert, 1985; Greenhof et al., 1986; Lacey et al., 1990; Nisell et al., 1994). These data also are consistent with reports of cholinergic innervation of the VTA from the mesopontine tegmentum (Satoh and Fibiger, 1986; Hallanger and Wainer, 1988; Cornwall et al., 1990). A recent report concerning the cholinergic innervation of the VTA and SNc from the mesopontine tegmentum (Oakman et al., 1995) has shown that there is a bilateral innervation of the VTA principally from the LDTg and an ipsilateral innervation of the SNc originating in central and anterior portions of the PPTg. In effect, taking the 

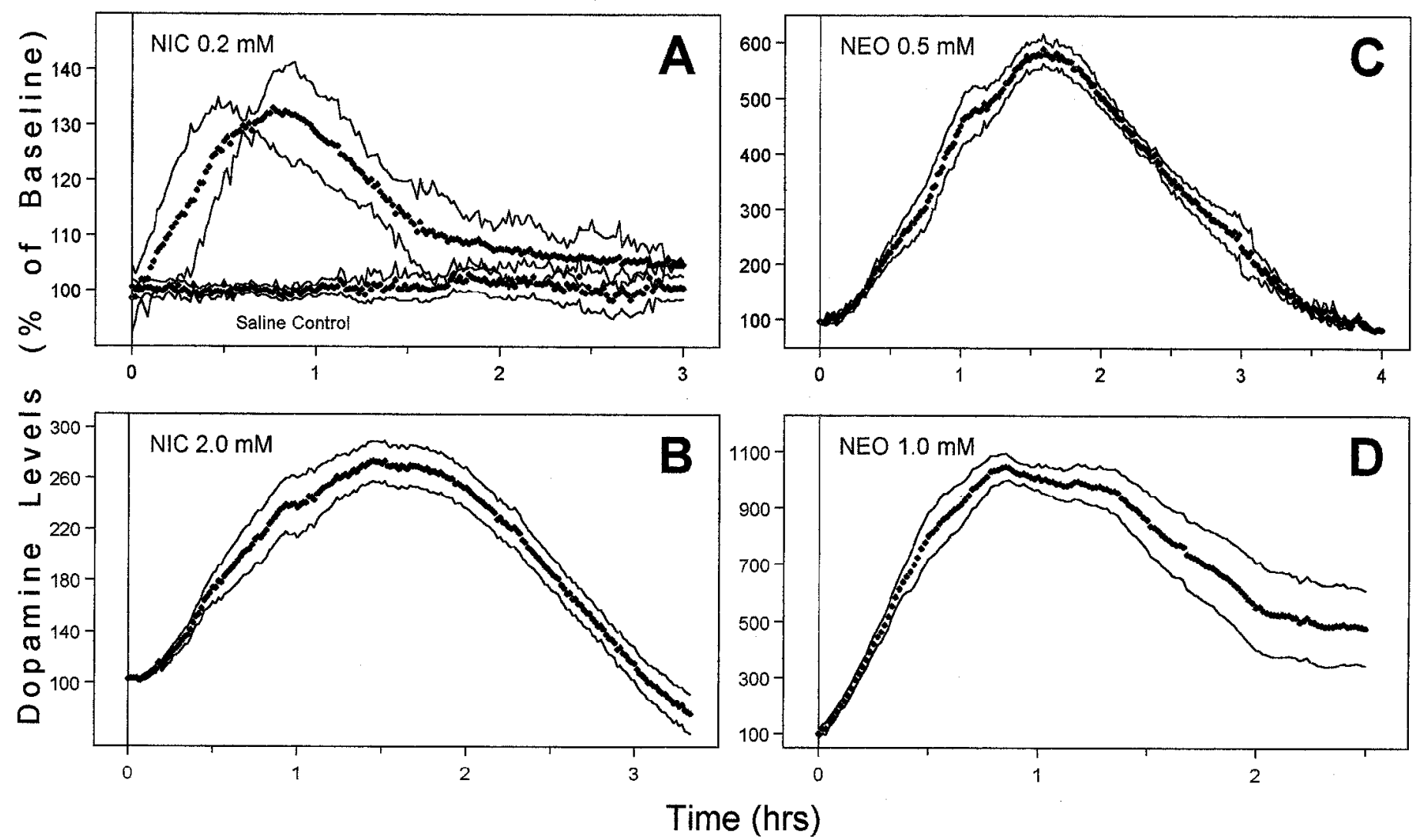

Figure 2. $A, B$, Chronoamperometric recordings depict the time courses of the effects of intra-VTA infusions of 0.2 and $2.0 \mathrm{~mm}$ nicotine $(N I C)$ and saline $(0.9 \% \mathrm{NaCl})$ on DA efflux in the nucleus accumbens. Effects of nicotine were significant $(p<0.01)$ over $90 \mathrm{~min}(0.2 \mathrm{mM}) \mathrm{and} 85 \mathrm{~min}(2.0 \mathrm{mM}) . C, D$, Chronoamperometric recordings depict the time courses of the effects of intra-VTA infusions of 0.5 and 1.0 mM neostigmine (NEO) on DA efflux in the nucleus accumbens. Effects of neostigmine were significant $(p<0.01)$ over $210 \mathrm{~min}(0.5 \mathrm{mM})$ and $240 \mathrm{~min}(1.0 \mathrm{mM})$. In all cases, solid lines represent the SEM. Chronoamperometric responses at 1 min intervals (rather than the $30 \mathrm{sec}$ intervals at which recordings were made) are presented for clarity.

mesopontine cholinergic neurons all together, there is an anterolateral-posteromedial gradient in the innervation of midbrain DA neurons; PPTg neurons tend to innervate the SNc, LDTg, and VTA. The present data add to this finding significantly by indi- cating functionally that lesions in the LDTg affect cholinergic activity in the VTA. These findings are in contrast to the effects of lesions in the PPTg, which affect cholinergic activity in the SNc to the extent that receptor supersensitivity develops in the SNc after

Table 1. Effects of intra-VTA microinjections of nicotine and neostigmine on DA efflux in the nucleus accumbens

Ipsilateral nucleus accumbens

\begin{tabular}{|c|c|c|c|c|c|c|c|c|c|c|c|}
\hline $\begin{array}{l}\text { Drug treat- } \\
\text { ment }\end{array}$ & $\begin{array}{l}\text { Dose } \\
(\mathrm{mM})\end{array}$ & $\begin{array}{l}\text { Maximal changc } \\
\text { in current }(\mathrm{nA})^{a}\end{array}$ & $\begin{array}{l}\text { Change from } \\
\text { baseline }(100 \%)^{b}\end{array}$ & $\begin{array}{l}\text { Timc } \\
(\min )^{c}\end{array}$ & $n$ & $\begin{array}{l}\text { Drug treat- } \\
\text { ment }\end{array}$ & $\begin{array}{l}\text { Dose } \\
(\mathrm{mM})\end{array}$ & $\begin{array}{l}\text { Maximal change } \\
\text { in current }(\mathrm{nA})^{a}\end{array}$ & $\begin{array}{l}\text { Change from } \\
\text { baseline }(100 \%)^{b}\end{array}$ & $\begin{array}{l}\text { Time } \\
(\min )^{c}\end{array}$ & $n$ \\
\hline SAL & 150 & $-0.02 \pm 0.03$ & $98 \pm 5$ & 50 & 4 & SAL & 150 & $+0.05 \pm 0.07$ & $105 \pm 7$ & 50 & 4 \\
\hline SAL & 150 & $+0.01 \pm 0.06$ & $101 \pm 6$ & 95 & 4 & SAL & 150 & $+0.11 \pm 0 . \hat{0} 4$ & $112 \pm 4$ & 95 & 4 \\
\hline NIC & 0.2 & $+0.31 \pm 0.07$ & $132 \pm 4^{*}$ & 50 & 5 & NIC & 0.2 & $+0.09 \pm 0.05$ & $109 \pm 5$ & 50 & 5 \\
\hline NIC & 2.0 & $+1.67 \pm 0.13$ & $276 \pm 14^{*}$ & 85 & 6 & NIC & 2.0 & $+0.48 \pm 0.16$ & $151 \pm 17^{*}$ & 85 & 6 \\
\hline NEO & 0.5 & $+4.56 \pm 0.34$ & $580 \pm 36^{*}$ & 95 & 5 & NEO & 0.5 & $+0.78 \pm 0.52$ & $181 \pm 27^{*}$ & 95 & 5 \\
\hline $\mathrm{NEO}$ & 1.0 & $+8.97 \pm 0.47$ & $1044 \pm 49^{*}$ & 50 & 5 & NEO & 1.0 & $+2.20 \pm 0.76$ & $332 \pm 80^{*}$ & 50 & 5 \\
\hline NEO-LDTg-X & 0.5 & $+1.28 \pm 0.10$ & $235 \pm 11^{*, * *}$ & 95 & 6 & NEO-LDTg-X & 0.5 & $+0.71 \pm 0.12$ & $174 \pm 13^{*}$ & 95 & 6 \\
\hline NEO-PPTg-X & 0.5 & $+4.01 \pm 0.21$ & $523 \pm 22^{*}$ & 95 & 4 & NEO-PPTg-X & 0.5 & $+1.19 \pm 0.47$ & $225 \pm 49^{*}$ & 95 & 4 \\
\hline NEO-Sham-X & 0.5 & $+4.66 \pm 0.37$ & $591 \pm 39^{*}$ & 95 & 3 & NEO-Sham-X & 0.5 & $+0.91 \pm 0.65$ & $196 \pm 68^{*}$ & 95 & 3 \\
\hline
\end{tabular}

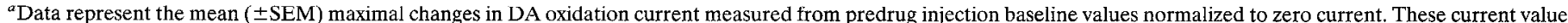

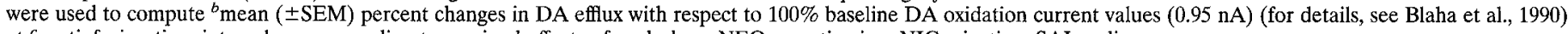
at ${ }^{c}$ postinfusion time intervals corresponding to maximal effects of each drug. NEO, neostigmine; NIC, nicotine; SAL, saline.

"Significant $(p<0.01)$ drug-induced percent changes in baseline versus SAL values at corresponding postinfusion time intervals.

${ }^{* *}$ Significant $(p<0.01)$ differences between drug-induced percent changes in baseline in LDTg ibotenate-lesioned rats versus sham- and PPTg-lesioned rats. 
Figure 3. Silhouettes of the largest and smallest PPTg (left) and LTDg (right) lesions shown on serial sections reproduced from the atlas of Swanson (1992). For convenience, all PPTg lesions are shown in the left hemisphere. Note that the lesions of PPTg and LDTg are entirely separated, the former lying lateral and anterior to the latter.

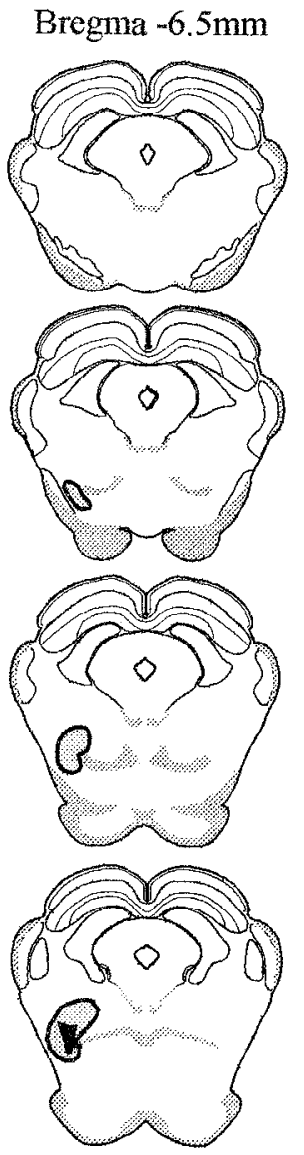

\section{I.: largest and smallest PPTg lesions $R$ : largest and smallest LDTg lesions}
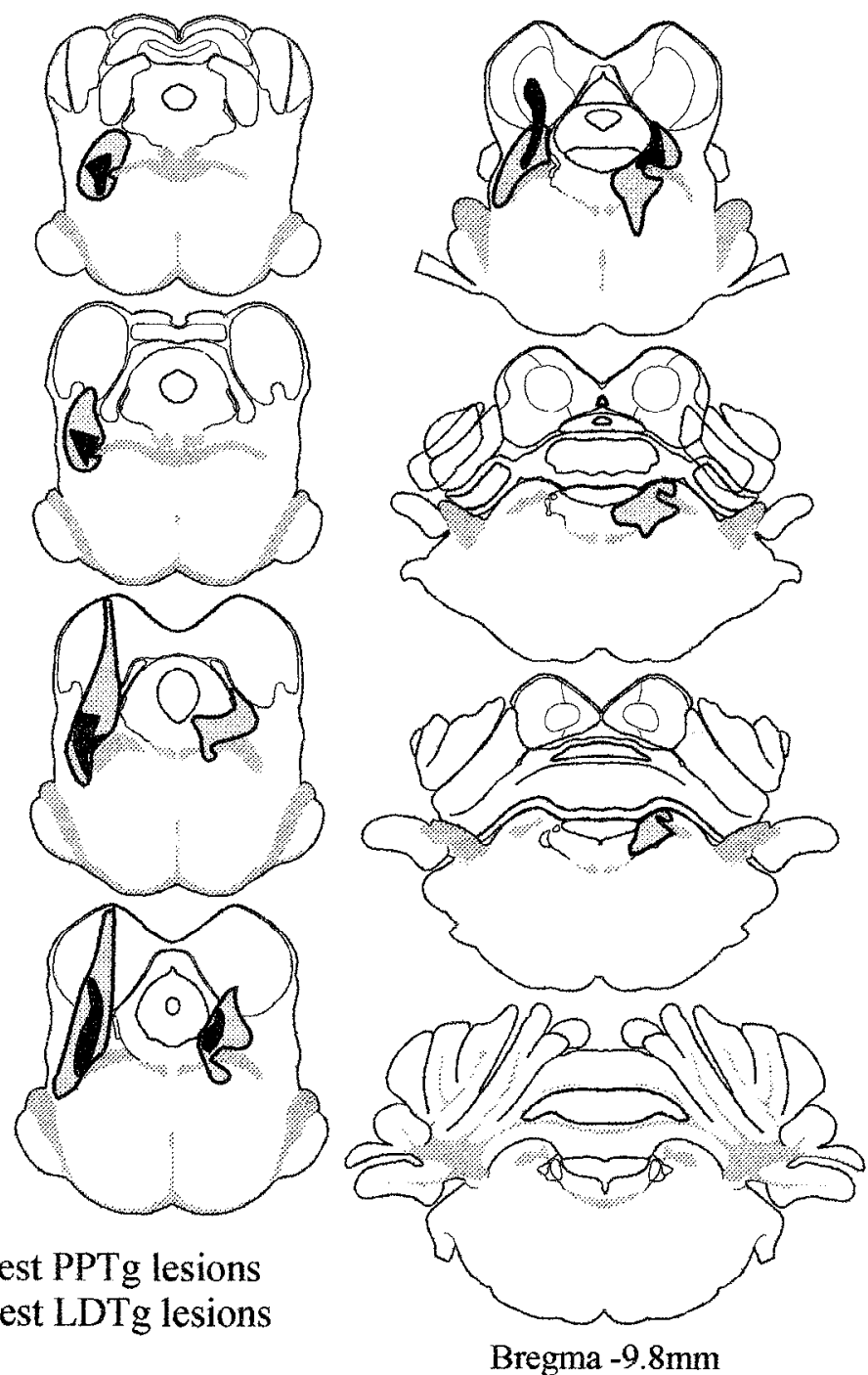

Bregma $-9.8 m m$ lesions selective for the PPT'g, but not LDI'g (Blaha and Winn, 1993). In the present study, PPTg lesions had no effect on cholinergic activity in the VTA.

\section{Neuroanatomical and methodological considerations}

Excitotoxins have been used in several previous studies to make lesions in the PPTg (Jones and Webster, 1988; Webster and Jones, 1988; Rugg ct al., 1992; Inglis et al., 1994a,b; Olmstead and Franklin, 1994) but, to the best of our knowledge, an excitotoxic lesion aimed exclusively at the LDTg has not heen reported previously. The anatomical data presented here show clearly that entirely separate ibotenate lesions can be made in the LDTg and PPTg. In no case did we observe damage in one site after lesion of the other. The SPTg, a structure incorporated into the PPTg by sume authors but classified as separate by others, was not affected by PPTg lesions, but spillage of toxin from the periaqueductal gray after LDTg lesions produced some loss of SPTg neurons. Further refinement of the LDTg lesion parameters should reduce this effect. Neither PPTg nor LDTg lesions were complete. In the case of the PPTg, loss of neurons was maximal in the compact portion of the nucleus, around the superior cerebellar peduncle, with the damage becoming less marked as the nucleus descends toward the substantia nigra. In the LDTg, there generally was complete damage in the central portion of the nucleus and less complete damage at the anterior and posterior poles. It is clear, however, that the lesions were entirely separale, and it is the separation of the two lesions that is the most important consideration. It is this differentiation that allows clear conclusions to be drawn concerning the separate innervations made by these two structures.

NADPH diaphorase is a nitric oxide synthase (Hope et al., 1991) found in many central nervous system neurons. In the mesopontine tegmentum, it is localized almost exclusively in cholinergic neurons in the PPTg, SPTg, and LDTg; in several studies, therefore, it has been used to label cholinergic neurons. We have shown a strong correlation between counts of neurons stained for NADPH diaphorase and those processed immunohistochemically to show CAT-positive neurons (Inglis et al., 1994a). The neuronal counts shown in Table 2 are raw, taken from $50 \mu \mathrm{m}$ sections cut every $200 \mu \mathrm{m}$ through the mesopontine tegmentum, but estimates of the total number of cholinergic neurons present made from the control data yield figures very close to those reported previously$\sim 1600$ neurons in both the PPTg and the LDTg (Rye et al., 1987; Rugg et al., 1992).

Unilateral cholinergic stimulation of the V'I'A produced clear and significant effects on DA efflux not only in the ipsilateral 



Figure 4. Representative photomicrographs showing Nissl-stained sections of LDTg- and PPTg-lesioned tissue and contralateral nonlesioned tissue. A, LDTg-lesioned tissue (area enclosed by the line). Note the survival of Me5 neurons around the edge of the central gray, the presence of reactive gliosis in the LDTg, and the absence of large cholinergic neurons (compare with $B$ ). Scale bar, $15 \mu \mathrm{m}$ (standard for all photomicrographs). $B$, LDTg control tissue. The area of the LDTg is approximated by the line. Note the presence of many large neurons in this area. NADPH diaphorase staining shows these to be nitric oxide synthase-positive and, therefore, presumably cholinergic. $C$, PPTg-lesioned tissue dominated by dense, reactive gliosis throughout the area. $D$, non-PPTg-lesioned tissue shows the position of the PPTg in relation to the superior cerebellar peduncle and lemniscal fibers. $4 V$, fourth ventricle; $L D T g$, laterodorsal tegmental nucleus; $L f$, lemniscal fibers; $M e 5$, mesencephalic trigeminal nucleus; $P P T g$, pedunculopontine tegmental nucleus; $s c p$, superior cerebellar peduncle.

nucleus accumbens, but also in the contralateral nucleus accumbens. Several studies have suggested the existence of a crossed VTA-accumbens pathway (Swanson, 1982; Björklund and Lindvall, 1986). The stimulation seen on the contralateral side in our experiments could represent activation of a crossed connection or could be accounted for by spread of drug to the contralateral VTA. It is worth considering that crossed VTA-to-nucleus accum- bens fibers would have been deafferented by lesions and, consequently, PPTg and LDTg lesions should have had the same effects on the ipsilateral and contralateral accumbens. The failure to find any effects of PPTg or LDTg lesions on the contralateral response indicates that this finding most likely was attributable to diffusion of drug from the injected VTA to the contralateral side. The doses used appear to be quite large, but several points need to be

Table 2. Mean ( \pm SEM) NADPH diaphorase-positive cell counts and lesion volumes for PPTg-, LDTg-, and sham-lesioned rats

\begin{tabular}{|c|c|c|c|c|}
\hline \multirow[b]{2}{*}{ Brain site } & \multicolumn{3}{|l|}{ Lesion site } & \multirow{2}{*}{$\begin{array}{l}\text { Lesion volume } \\
\left(\mathrm{mm}^{3}\right)\end{array}$} \\
\hline & Control & LDTg & PPTg & \\
\hline LDTg & $\begin{aligned} 413.1 & \pm 19.0 \\
(100 & \pm 5 \%)\end{aligned}$ & $\begin{array}{r}196.4 \pm 47.0 \\
(48 \pm 11 \%)\end{array}$ & $\begin{aligned} 440.5 & \pm 53.9 \\
(107 & \pm 13 \%)\end{aligned}$ & $1.55 \pm 0.43$ \\
\hline PPTg & $\begin{aligned} 383.0 & \pm 26.1 \\
(100 & \pm 7 \%)\end{aligned}$ & $\begin{aligned} 383.8 & \pm 40.8 \\
(100 & \pm 11 \%)\end{aligned}$ & $\begin{aligned} 211.3 & \pm 42.3 \\
(55 & \pm 11 \%)\end{aligned}$ & $4.81 \pm 1.01$ \\
\hline SPTg & $\begin{aligned} 153.3 & \pm 10.9 \\
(100 & \pm 7 \%)\end{aligned}$ & $\begin{array}{r}107.0 \pm 12.8 \\
(70 \pm 8 \%)\end{array}$ & $\begin{aligned} 179.0 & \pm 36.4 \\
(117 & \pm 24 \%)\end{aligned}$ & ND \\
\hline
\end{tabular}

These are the mean numbers of neurons counted on $50 \mu \mathrm{m}$ sections taken through the mesopontine tegmentum at $200 \mu \mathrm{m}$ intervals. Estimates of the total populations of cholinergic neurons derived from these counts ( $\sim 1600$ in PPTg and LDTg) are similar to those reported previously (Rye et al., 1987; Rugg et al., 1992). ND, not determined. Figures in parentheses are percentages of appropriate control values $(100 \%)$. "Significant $(p<0.01)$ differences compared with appropriate control values. 

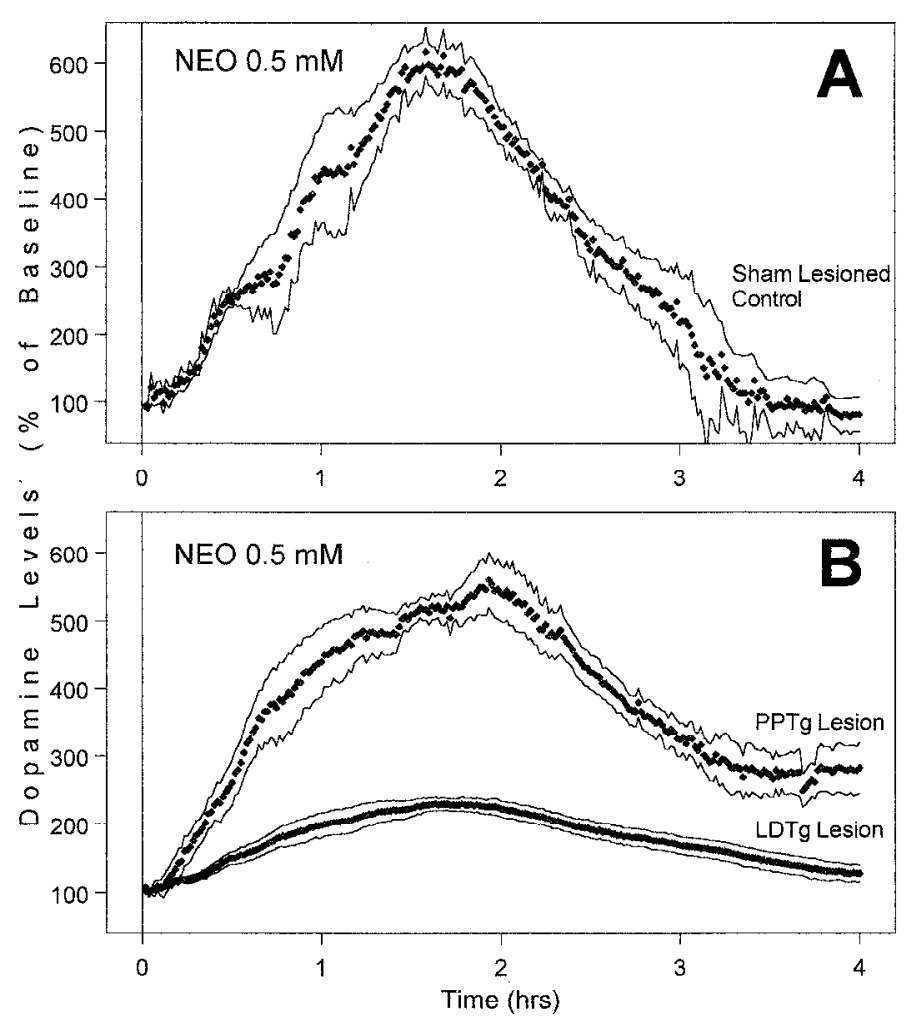

Figure 5. A, Chronoamperometric recordings show the time courses of the stimulatory effects of intra-VTA injections of $0.5 \mathrm{~mm}$ neostigmine $(N E O)$ in sham-lesioned rats. $B$, Chronoamperometric recordings show the time courses of the stimulatory effects of intra-VTA injections of 0.5 $\mathrm{mM}$ neostigmine $(N E O)$ in PPTg-and LDTg-lesioned rats. Effects of neostigmine differed significantly $(p<0.01)$; sham-lesioned and PPTglcsioncd rats did not differ from each other (or from intact rats treated with $0.5 \mathrm{~mm}$ neostigmine), but LDTg-lesioned rats differed from all others Points represent the mean changes in the chronoamperometric responses, and solid lines represent the SEM. Chronoamperometric responses at 1 min intervals (rather than the $30 \mathrm{sec}$ intervals at which recordings were made) are presented for clarity.

considered. First, the doses are compatible with those used in the SNc (Blaha and Winn, 1993). Second, a large portion of microinjected fluid is lost rapidly from the brain (Myers and Hoch, 1978). Third, behavioral studies using these doses have produced predictable increases in normal behavior (Winn, 1991; Parker et al., 1993), consistent with the DA efflux observed in anesthetized rats. This suggests that similar electrochemical results could be obtained in both conditions.

One point of contrast between the previous study, in which DA effux in the caudate-putamen was measured after cholinergic stimulation of the SNc, and the present study concerns the difference in response to nicotine and neostigmine. Slightly different doses of nicotine were used in the two studies, but the effects on striatal DA efflux essentially were similar. In contrast, the effects of neostigmine in the VTA were much greater than those in the SNc. The maximal percentage effect of the lowest dose of neostigmine $(125 \mathrm{pmol})$ injected into the $\mathrm{SNc}$ was $111 \%$; for the highest dose $(250 \mathrm{pmol})$, this effect was $227 \%$. In contrast, the VTA maximal percentage effects were 580 and $1044 \%$ (125 and 250 pmol, respectively). It is not clear why neostigmine had a fourfold greater effect on accumbens DA efflux compared with the caudate-putamen. The density of the cholinergic innervation of the VTA compared with the SNc, the volume or concentration of
ACh present, and the efficiency of AChE in the VTA all are possible causes for these differences. An explanation in terms of receptor differences is less likely given the similar effects of nicotine after microinjection into either the VTA or the SNc.

\section{Mesopontine cholinergic innervation of midbrain DA neurons}

The importance of this work has been emphasized by recent suggestions that, in some cases at least, there are increases in the numbers of mesopontine cholinergic neurons in the brains of schizophrenics (Garcia-Rill et al., 1995) (but see also Lweig et al., 1994) and, as has been indicated by others (Yeomans, 1995), such changes have implications for the regulation of midbrain DA neurons. Mesopontine cholinergic neurons generally are considered to be part of the ascending reticular activating system (Mesulam et al., 1989; Harrison et al., 1990), and many studies show that they have a role in the maintenance of sleep and arousal (Semba et al., 1990; Steriade et al., 1990; Harrison et al., 1990). In particular, they regulate the state of the thalamus, aiding the transition from burst-firing to single-spiking modes of operation (Steriade and Llinas, 1988; Steriade et al., 1990; Kamondi et al., 1992; Williams et al., 1994), and are thought to be crucial in the control of behavioral state. In addition to controlling thalamic operations, the previous and present data suggest that mesopontine cholinergic neurons also regulate midbrain DA neurons, an operation that is consistent with behavioral state control, given that midbrain DA neuronal activity has been associated with behavioral activation and response to novel stimuli (Romo and Schultz, 1990; Schultz and Romo, 1990; Ljungberg et al., 1992). Although a cholinergic presence in both the VTA and the SNc has been recognized for many years, the functional data we have presented argue strongly that it is the LDTg cholinergic neurons that impact on the VTA, whereas PPTg cholinergic neurons affect the $\mathrm{SNc}$, and that this separation is almost complete. This is paralleled by the cholinergic innervation of the thalamus. $\mathrm{Al}$ though not as sharply defined, it is clear that PPTg cholinergic neurons innervate sensory and motor nuclei of the thalamus (such as the geniculate nuclei, several of the lateral nuclei, and the ventrobasal complex) strongly, whereas LDTg neurons provide the bulk of the innervation of limbic nuclei such as the mediodorsal nucleus (Hallanger et al., 1987). We speculate, therefore, that although the ascending cholinergic neurons of the PPTg and LDTg innervate similar sites (thalamic nuclei and midbrain DA neuron), there is an anatomical separation such that PPTg neurons are associated with "sensorimotor" systems, whereas the LDTg neurons are associated with "limbic" systems. In further experiments, we will determine what functional differentiation exists between these cholinergic systems and the extent to which the innervations of thalamus and midbrain are collateralized.

\section{REFERENCES}

Beninato M, Spencer RF (1987) A cholinergic projection to the rat substantia nigra from the pedunculopontine tegmental nucleus. Brain Res 412:169-174.

Beninato M, Spencer RF (1988) The cholinergic innervation of the rat substantia nigra: a light and electron microscopic immunohistochemical study. Exp Brain Res 72:178-184.

Björklund A, Lindvall O (1986) Catecholaminergic brain stem regulatory systems. In: Handbook of physiology: the nervous system, Vol IV (Mountcastle VB, Bloom FE, Geiger SR, eds), pp 115-235. Bethesda: American Physiological Society.

Blaha CD, Jung ME (1991) Electrochemical evaluation of stearatemodified graphite paste electrodes: selective detection of dopamine is maintained after exposure to brain tissue. J Electroanal Chem 310:317-334. 
Blaha CD, Lane RF (1983) Chemically modified electrode for in vivo monitoring of brain catecholamines. Brain Res Bull 10:861-864.

Blaha CD, Phillips AG (1992) Pharmacological evidence for common mechanisms underlying the cffects of neurotensin and neuroleptics on in vivo dopamine efflux in the rat nucleus accumbens. Neuroscience 49:867-877.

Blaha CD, Winn P (1993) Modulation of dopamine efflux in the striatum after cholinergic stimulation of the substantia nigra in intact and pedunculopontine tegmental nucleus-lesioned rats. J Neurosci 13:1035-1044.

Blaha CD, Coury A, Fibiger HC, Phillips AG (1990) Effects of neurotensin on dopamine release and metabolism in the rat striatum and nucleus accumbens: cross-validation using in vivo voltammetry and microdialysis. Neuroscience 34:699-705.

Bolam JP, Francis CM, Henderson Z (1991) Cholinergic input to dopaminergic neurons in the substantia nigra: a double immunocytochemical study. Neuroscience 41:483-494.

Butcher LL, Marchand R (1978) Dopamine neurons in pars compacta of the substantia nigra contain acetylcholinesterase: histochemical correlations on the same brain section. Eur J Pharmacol 52:415-417.

Clarke PBS, Pert A (1985) Autoradiographic evidence for nicotinic receptors on nigrostriatal and mesolimbic dopaminergic neurons. Brain Res 348:355-358.

Clarke PBS, Hommer DW, Pert A, Skirboll LR (1987) Innervation of substantia nigra neurons by cholinergic afferents from pedunculopontine nucleus in the rat: neuroanatomical and electrophysiological evidence. Neuroscience 23:1011-1019.

Cornwall J, Cooper JD, Phillipson OT (1990) Afferent and efferent connections of the laterodorsal tegmental nucleus in the rat. Brain Res Bull 25:271-284.

Druhan JP, Fibiger HC, Phillips AG (1989) Differential effects of cholinergic drugs on discriminative cues and self-stimulation produced by electrical stimulation of the ventral tegmental area. Psychopharmacology $97: 331-338$.

Dunbar JS, Hitchcock K, Latimer M, Rugg EL, Ward N, Winn P (1992) Excitotoxic lesions of the pedunculopontine tegmental nucleus of the rat. II. Examination of eating and drinking, rotation, and reaching and grasping following unilateral ibotenate or quinolinate lesions. Brain Res $589: 194-206$

Garcia-Rill E, Biedermann JA, Chambers T, Skinner RD, Mrak RE, Husain M, Karson CN (1995) Mesopontine neurons in schizophrenia. Neuroscience 66:321-335.

Gould E, Woolf NJ, Butcher LL (1989) Cholinergic projections to the substantia nigra from the pedunculopontine and laterodorsal tegmental nuclei. Neuroscience 28:611-23.

Greenfield S $\Lambda$, Cheramy $\Lambda$, Leviel V, Glowinski J (1980) In vivo release of acetylcholinesterase in cat substantia nigra and caudate nucleus. Nature 284:355-357.

Grenhoff J, Aston-Jones G, Svensson TH (1986) Nicotinic effects on the firing pattern of midbrain dopamine neurons. Acta Physiol Scand 128:351-358

Hallanger AE, Wainer BH (1988) Ascending projections from the pedunculopontine tegmental nucleus and the adjacent mesopontine tegmentum in the rat. J Comp Neurol 274:483-515.

Hallanger AE, Levey AI, Lee HJ, Rye DB, Wainer BH (1987) The origins of cholinergic and other subcortical afferents to the thalamus in the rat. J Comp Neurol 262:105-124.

Harrison JB, Woolf NJ, Buchwald JS (1990) Cholinergic neurons of the feline pontomesencephalon. I. Essential role in "wave A" generation. Brain Res 520:43-54.

Hernandez-Lopez S, Gongora-Alfaro JL, Martinez-Fong D, Aceves J (1992) A cholinergic input to the substantia nigra pars compacta increases striatal dopamine metabolism measured by in vivo voltammetry. Brain Res 598:114-120.

Hope BT; Michael GJ, Knigge KM, Vincent SR (1991) Neuronal NADPH-diaphorase is a nitric oxide synthase. Proc Natl Acad Sci USA 88:2811-2814

Inglis WL, Allen LF, Whitclaw RB, Latimer MP, Brace IIM, Winn P (1994a) An investigation into the role of the pedunculopontine tegmental nucleus in the mediation of locomotion and orofacial stereotypy induced by $D$-amphetamine and apomorphine in the rat. Neuroscience $58: 817-833$.

Inglis WL, Dunbar JS, Winn P (1994b) Outflow from the nucleus accumbens to the pedunculopontine tegmental nucleus: a dissociation between locomotor activity and the acquisition of responding for condi- tioned reinforcement stimulated by D-amphetamine. Neuroscience 62:51-64

Jacobowitz DM, Goldberg AM (1977) Determination of acetylcholine in discrete regions of the rat brain. Brain Res 122:575-577.

Jones BE, Webster HH (1988) Neurotoxic lesions of the dorsolateral pontomesencephalic tegmentum-cholinergic cell area in the cat. I. Effects upon cholinergic innervation of the brain. Brain Res 451:13-32.

Kamondi A, Williams JA, Hutcheon B, Reiner PB (1992) Membrane properties of mesopontine cholinergic neurons studied with the wholecell patch-clamp technique: implications for behavioural state control. J Neurophysiol 68:1359-1371.

Lacey MG, Calabresi P, North RA (1990) Muscarinc depolarizes rat substantia nigra zona compacta and ventral tegmental neurons in vitro through $\mathbf{M}_{1}$-like receptors. J Pharmacol Exp Ther 253:395-400.

Lavoie B, Parent A (1994) Pedunculopontine nucleus in the squirrel monkey: cholinergic and glutamatergic projections to the substantia nigra. J Comp Neurol 344:232-241.

Lee HJ, Rye DB, Hallanger AE, Levey AI, Wainer BH (1988) Cholinergic vs. non-cholinergic efferents from the mesopontine tegmentum to the extrapyramidal motor system nuclei. J Comp Neurol 275:469 - 492.

Lehmann J, Fibiger HC (1978) Acetylcholinesterase in the rat substantia nigra and caudate-putamen of the rat: properties and localization in dopaminergic neurons. J Neurochem 30:615-624

Ljungberg T, Apicella P, Schultz W (1992) Responses of monkey dopamine neurons during learning of behavioral reactions. J Neurophysiol 67:145-163

Mesulam M-M, Geula C, Bothwell MA, Hersh LB (1989) Human reticular formation: cholinergic neurons of the pedunculopontine and laterodorsal tegmental nuclei and some cytochemical comparisons to forebrain cholinergic neurons. J Comp Neurol 281:611-633.

Myers RD, Hoch DB (1978) ${ }^{14} \mathrm{C}$-Dopanine microinjected into the brain stem of the rat: dispersion kinetics, site content and functional dose. Brain Res Bull 3:601-609.

Nastuk MA, Graybiel AM (1991) Pharmacologically defined M1 and M2 muscarinic cholinergic binding sites in the cat's substantia nigra: development and maturity. Dev Brain Res 61:1-10.

Nisell M, Nomikos GG, Svensson TH (1994) Systemic nicotine-induced dopamine release in the rat nucleus accumbens is regulated by nicotinic receptors in the ventral tegmental area. Synapsc 16:36-44.

Oakman SA, Faris PL, Kerr PE, Cozzari C, Hartman BK (1995) Distribution of pontomesencephalic cholinergic neurons projecting to substantia nigra differs significantly from those projecting to ventral tegmental area. J Neurosci 15:5959-5869.

Olmstead MC, Franklin KBJ (1994) Lesions of the pedunculopontine tegmental nucleus block drug-induced reinforcement, but not amphetamine-induced locomotion. Brain Res 638:29-35.

Parker GC, Inglis WL, Winn P (1993) A comparison of behaviour following stimulation of the anterior substantia nigra by direct and indirect cholinergic agonists. Psychopharmacology 112:242-248.

Parker GC, Rugg EL, Winn P (1991) Cholinergic stimulation of substantia nigra: abolition of carbachol-induced eating by unilateral 6-hydroxydopamine lesion of nigrostriatal dopamine neurons. Exp Brain Res 87:597-603.

Paxinos G, Watson C (1986) The rat brain in stereotaxic coordinates, 2nd ed. New York: Academic

Romo R, Schultz W (1990) Dopamine neurons of the monkey midbrain: contingencies of responses to active touch during self-initiated arm movements. J Neurophysiol 63:592-606.

Rugg EL, Dunbar JS, Latimer M, Winn P (1992) Comparison of the neurotoxic properties of various excitotoxins in the pedunculopontine tegmental nucleus of the rat, with particular reference to the loss of immunohistochemically identified cholinergic neurons. Brain Res 589:181-193.

Rye DB, Saper CB, Lee HJ, Wainer BH (1987) Pedunculopontine tegmental nucleus of the rat: cytoarchitecture, cytochemistry, and some extrapyramidal connections of the mesopontine tegmentum. J Comp Neurol 259:483-528.

Satoh K, Fibiger HC (1986) Cholinergic neurons of the laterodorsal tegmental nucleus: efferent and afferent connections. J Comp Neurol 253:277-302

Schultz W, Romo R (1990) Dopamine neurons of the monkey midbrain: contingencies of responses to stimuli eliciting immediate behavioral reactions. J Neurophysiol 63:607-624. 
Semba K, Reiner PB, Fibiger HC (1990) Single cholinergic mesopontine tegmental neurons project to both the pontine reticular formation and the thalamus in the rat. Neuroscience 38:643-654.

Steriade M, Llinas RR (1988) The functional states of the thalamus and the associated neuronal interplay. Physiol Rev 68:649-742.

Steriade M, Datta S, Pare D, Oakson G, Curro'Dossi R (1990) Neuronal activities in brain-stem cholinergic nuclei related to tonic activation processes in thalamocortical systems. J Neurosci 10:2541-2559.

Swanson LW (1982) The projections of ventral tegmental area and adjacent regions: a combined fluorescent retrograde tracer and immunofluorescence study in the rat. Brain Res Bull 9:321-353.

Swanson LW (1992) Brain maps: structure of the rat brain. Amsterdam: Elsevier.

Tokıno H, Moriizumi T, Kudo M, Nakamura Y (1988) Morphological evidence for monosynaptic projections from the nucleus tegmenti pedunculopontinus pars compacta to nigrostriatal projection neurons. Neurosci Lett 85:1-4.

Vincent SR, Kimura H (1992) Hislochemical mapping of nitric oxide synthase in the rat brain. Neuroscience 46:755-784.
Webster HH, Jones BE (1988) Neurotoxic lesions of the dorsolateral pontomesencephalic tegmentum-cholinergic cell area in the cat. II. Effects upon sleep-waking states. Brain Res 458:285-302.

Williams JA, Comisarow J, Day J, Fibiger HC, Reiner PB (1994) Statedependent release of acetylcholine in rat thalamus measured by in vivo microdialysis. J Neurosci 14:5236-5242.

Winn P (1991) Cholinergic stimulation of substantia nigra: effects on feeding, drinking and sexual behaviour in the male rat. Psychopharmacology 104:208-214.

Woolf NJ, Butcher LL (1986) Cholinergic systems of the rat brain. III. Projections from the pontomesencephalic tegmentum to the thalamus, tectum, basal ganglia, and basal forebrain. Brain Res Bull 16:603-637.

Yeomans JS (1995) Role of tegmental cholinergic neurons in dopaminergic activation, antimuscarinic psychosis and schizophrenia. Neuropsychopharmacology 12:3-16.

Zweig RM, Manaye KF, Cook C, Swiergiel TJ, German DC (1994) Preliminary investigation of the pedunculopontine nucleus in schizophrenia. Soc Neurosci Abstr 20:622. 